\title{
Phenotypic and Functional Changes in Peripheral Blood Monocytes during Progression of Human Immunodeficiency Virus Infection \\ Effects of Soluble Immune Complexes, Cytokines, Subcellular Particulates from Apoptotic Cells, and HIV-1-encoded Proteins on Monocyte Phagocytic Function, Oxidative Burst, Transendothelial Migration, and Cell Surface Phenotype
}

\begin{abstract}
JoAnn Trial, ${ }^{1}$ Holly H. Birdsall,, $\|^{\mid \S}$ Jennifer A. Hallum,' Martin L. Crane,, Maria C. Rodriguez-Barradas,' Andrew L. de Jong, ${ }^{5}$ Bhuvaneswari Krishnan,"* Christine E. Lacke, Carl G. Figdor, ${ }^{\ddagger}$ and Roger D. Rossen ${ }^{14 *}$

*Research Center for AIDS and HIV-related Infections, the Immunology Research Laboratory and the Laboratory Service at the Veterans Affairs Medical Center, Houston, Texas 77030; ${ }^{\ddagger}$ the Netherlands Cancer Institute, Amsterdam, Netherlands; and the Departments of ${ }^{8}$ Otorhinolaryngology, "Microbiology and Immunology, 'Medicine, and **Pathology at Baylor College of Medicine, Houston, Texas 77030; ${ }^{\ddagger}$ Division of Medicine, Education \& Research, Greenville Hospital System, Greenville, North Carolina 29605
\end{abstract}

\begin{abstract}
We postulated that changes in the cell surface display of molecules that facilitate cell-cell and cell-matrix adhesions may reflect the changing immunosurveillance capacity of blood monocytes during progression of human immunodeficiency virus (HIV) infections. In Centers for Disease Control (CDC) stage A patients, whose monocytes' ability to phagocytose bacteria and generate reactive oxygen intermediates is often increased, the frequency of monocytes expressing CD49d, HLA-DP, HLA-DQ, and an activation epitope of CD11a/CD18 was increased and monocyte transendothelial migration was unimpaired. In CDC stage B/C patients, whose monocytes' ability to phagocytose bacteria and migrate across confluent endothelial monolayers was diminished, surface expression of CD49e and CD62L and the percentage of monocytes expressing CD18, CD11a, CD29, CD49e, CD54, CD58, CD31, and HLA-I were significantly decreased. Incubating normal donor monocytes with immune complexes in vitro reproduced the phenotypic and functional abnormalities seen in stage $B / C$ patients. By contrast, in vitro stimulation with subcellular particulates released by apoptotic lymphocytes reproduced changes seen in stage A patients' monocytes. Although circulating monocytes appear to be activated at all stages, these data suggest that the high levels of circulating immune complexes, found predominantly in the later stages of HIV infection, may be particularly instrumental in reducing the monocyte's capacity to maintain surveillance against infection. ( J. Clin. Invest. 1995. 95:1690-1701.) Key words: HIV • monocyte • phagocytosis • antigen-antibody complex • apoptosis
\end{abstract}

\section{Introduction}

After the onset of human immunodeficiency virus (HIV) infection there is often a latent period during which infected individuals remain asymptomatic even though the virus continues to

Address correspondence to JoAnn Trial, Ph.D., Research Center for AIDS and HIV-related Infections, Bldg 109, Rm 147, Houston VA Medical Center, 2002 Holcombe Blvd., Houston, TX 77030. Phone: 713-794-7582; FAX 713-790-9141.

Received for publication 25 August 1994 and in revised form 14 December 1994.

The Journal of Clinical Investigation, Inc.

Volume 95, April 1995, 1690-1701 replicate in lymphoid tissues $(1,2)$. During this interval, when patients have not yet experienced significant bacterial or fungal infections, the ability of their circulating monocytes and pulmonary alveolar macrophages to phagocytose microorganisms, generate reactive oxygen intermediates (ROIs), ${ }^{1}$ and kill ingested bacteria remains within normal limits and in some cases may be greater than in normal controls $(3,4)$. Even direct HIV infection of monocytes in vitro does not immediately impair the ability of these cells to phagocytose bacteria, generate ROIs, and kill opsonized Escherichia coli or Candida albicans (5), although with prolonged culture, infected monocytes can become dysfunctional (6). Retention of monocyte antibacterial activity, early in HIV-1 infection, is consistent with the observation that infection with this virus causes monocytoid cells to differentiate and display molecules that actually facilitate cellcell adhesive interactions $(7,8)$.

Eventually, critical monocyte functions decline in vivo (9, $10)$, and their ability to respond to chemotactic stimuli (11), phagocytose bacteria (12), and clear opsonized particles from the circulation (13) may become impaired, although their ability to phagocytose and kill Cryptococcus neoformans, Aspergillus fumigatus, and other fungi may remain intact for some time (14).

To identify the molecular basis for the apparent decline in monocyte/macrophage function during the course of HIV infection, we have studied the cell surface phenotypes, phagocytic activity, reactive oxygen production, and transendothelial migratory capacity of peripheral blood monocytes from asymptomatic HIV-infected patients and patients who have experienced one or more serious infections, under the hypothesis that changes in the expression of specific cell surface molecules may play a role in the development of the observed functional defects. By means of in vitro studies, we have attempted to model the changes observed in vivo and have identified factors that are likely to cause the observed abnormalities.

\section{Methods}

Experimental subjects. 74 patients were recruited from the outpatient clinic for HIV-infected individuals at the VA Medical Center, Houston, TX, under a protocol approved by the institutional review board and

1. Abbreviations used in this paper: $\mathrm{CDC}$, Centers for Disease Control; CH50, estimate of total hemolytic complement activity; DCFDA, dihydrochlorofluorescein diacetate (C400); MCF, mean channel fluorescence; MNL, mononuclear leukocyte; NK, natural killer; PE, phycoerythrin; ROI, reactive oxygen intermediate. 
staged according to current criteria of the Centers for Disease Control (CDC) (15). None had or had had an opportunistic infection within the 4-wk period before these studies. Healthy men were recruited from laboratory and hospital personnel. Venous blood was collected in polypropylene syringes, using preservative-free, pharmaceutical grade heparin (Squibb-Marsam, Inc., Cherry Hill, NJ). Blood was also collected without anticoagulant and with EDTA to provide serum and plasma, respectively. These were stored at $-70^{\circ} \mathrm{C}$ until tested.

Because of the time required and quantities of blood needed for each of the several assays, it was not possible to perform all measurements on the same blood sample in a single day. Therefore, distinct groups of patients were recruited to study monocyte cell surface phenotype, phagocytic function and ROI production, and transendothelial migration. Samples from one or more healthy control donors were tested concurrently with each patient sample, using identical reagents under identical conditions. Monocyte cell surface phenotypes were evaluated in 25 patients, using a comprehensive panel of mAbs. Next, we examined the relationship between cell surface molecules shown to be abnormally displayed on monocytes of HIV-infected subjects (summarized in Table II) and the capacity of monocytes to phagocytose bacteria and generate ROIs. Monocyte phagocytosis and ROI production were studied in 23 patients; methods developed for these evaluations and the results of studies in the 13 patients classified as CDC stage $A$ have been previously reported (3); the results obtained in the 10 patients classified as CDC stage B/C are reported here. Finally, we measured mononuclear leukocyte (MNL) migration across endothelial monolayers with blood from 26 patients. The methods developed to investigate this behavior and the results of tests on blood from 17 stage A patients have previously been reported (15). Additional studies of the effects of HIV infection on the ability of lymphocytes to migrate across confluent endothelium will be reported separately (Birdsall, H. H., J. Trial, A. L. de Jong, L. K. Green, A. H. Laughter, and R. D. Rossen, manuscript submitted for publication.)

Reagents. mAbs (clone numbers in parentheses) against CDs 31 (clone 5.6E), 32 (clone 2E1), 34 (clone QBEND 10), 36 (clone FA6.152), 41a (clone P2), 44 (clone J173), 49e (clone SAM 1), 49f (clone GoH3), 57 (clone NC1), 58 (clone AICD58), 61 (clone SZ 21), and 71 (clone YDJ1.22) were obtained from Amac, Inc. (Westbrook, ME). A hybridoma producing a mAb against an MHC class $I$ framework antigen (clone BB7.5) was obtained from the American Type Culture Collection (Rockville, MD). Antibodies against CDs 4 (Leu-3a + 3b) (clones SK3, SK4), 11c (clone SHCL-3), 15 (clone MMA), 16 (clone GO22), 19 (clone 4G7), 33 (clone P67.6), 35 (clone 44D), and 45 (clone 2D1), HLA-DP (clone B7/21), HLA-DQ (clone SK10), and HLA-DR (clone L243), as well as T cell receptors (TCRs) $\alpha / \beta$ (clone WT31) and $\gamma / \delta$ (clone 11F2), were obtained from Becton Dickinson (San Jose, CA). Phycoerythrin (PE)-conjugated mAbs against CD14 (clone 116) and unconjugated mAbs against CDs 11b (clone 94) and 56 (clone 3B8) were obtained from Coulter Immunology (Hialeah, FL). NKI-L16, a mAb against the activated form of CD11a, was prepared and characterized as previously described (16). AntiCD64 (clone 32.2) was obtained from Medarex, Inc. (West Lebanon, $\mathrm{NH}$ ). Anti-CD29 (clone 18D3) and anti-CD49d (clone 20E4) were gifts from Dr. B. W. McIntyre (M. D. Anderson Cancer Center, Houston, TX). Antibody 20E4 is directed against a different epitope of CD49d than L25, a standard anti-CD49d (17). Antibodies against CD11a (clone R3.1), CD18 (clone R15.7), and CD54 (clone RR1/ 1) (18) were gifts from Dr. Robert Rothlein (Boehringer-Ingelheim Pharmaceuticals, Inc., Ridgefield, CT). Anti-CD62L (L-selectin) (clone DREG56) (19) was a gift of Dr. Wayne Smith (Baylor College of Medicine, Houston, TX). Antibodies against CD49b (clone P1E 6) and CD49c (clone P1B 5) were obtained from Telios Pharmaceuticals, Inc. (San Diego, CA). A mAb to the CD4 domain of HIV-1 gp120 (clone 1536) that reacts with the site in gp120 that binds to CD4 (20) was a gift from Dr. Michael Fung (Tanox Biosystems, Houston, TX). Isotype controls were obtained from Coulter Immunology except for IgG3, which was from Zymed Laboratories, Inc. (South San Francisco, CA) A single lot of $\mathrm{mAbs}$ was used for each antigen in tests of both patients and controls. The secondary antibody was FITC-conjugated $\mathrm{F}\left(\mathrm{ab}^{\prime}\right)_{2}$ affinity-purified sheep anti-mouse Ig (not cross-reactive with human Ig) from Cappel (Organon Teknika Corp., West Chester, PA).

Zymosan, LPS from E. coli serotype 0127:B8, and purified human IgG were obtained from Sigma Chemical Co. (St. Louis, MO). IgG was aggregated at a concentration of $2 \mathrm{mg} / \mathrm{ml}$ in veronal-buffered saline, $\mathrm{pH} 7.4$, at $63^{\circ} \mathrm{C}$ for $20 \mathrm{~min}$. E. coli strain $\mathrm{HB} 101$ was obtained from Dr. Michael McShan and Streptococcus pneumoniae strain 14 was from Dr. David Watson (both at the VA Medical Center, Houston, TX). Recombinant cytokines were obtained from Genzyme Corp. (Boston, MA). Recombinant HIV-1 proteins, gp120, gp160, rev, nef, tat, p24, and reverse transcriptase were obtained from American Bio-Technologies, Inc. (Cambridge, MA).

Immunofluorescence studies of blood leukocytes. Heparinized blood was distributed in 0.1-ml aliquots into polypropylene tubes for incubation with saturating concentrations of primary or secondary antibodies at $4^{\circ} \mathrm{C}$ for $30 \mathrm{~min}$. Incubations were separated by two washes with icecold Dulbecco's PBS (Gibco Laboratories, Grand Island, NY). FITCconjugated sheep anti-mouse Ig was used at a dilution of 1:120. PEconjugated anti-CD14, added after the secondary antibody, was used according to the manufacturer's directions. After leukocytes were stained and washed, red cells were lysed with FACS Lysing Solution (Becton Dickinson). Leukocytes were washed again, fixed in 1\% paraformaldehyde, and analyzed by flow cytometry the day of the experiment. Leukocytes routinely lacked adherent activated platelets, as shown by testing with mAb to GMP-140 (CD62, Immunotech, Marseilles, France). Total white blood cell (Coulter Counter, Coulter Electronics, Hialeah, FL) and differential counts were measured in aliquots of the same blood samples used for immunofluorescence studies. Tests of control blood donors were randomly interspersed among patient samples.

Flow cytometry was performed on an Epics Profile I (Coulter Cytometry, Hialeah, FL) with an argon laser tuned to $488 \mathrm{~nm}$ and with three fluorescence channels. Daily alignment and calibration of the instrument were done with DNA-check and Standard-Brite fluorescent beads (Coulter Corp.). Green (FL1), orange (FL2), and red (FL3) fluorescence signals were measured on a four-decade logarithmic scale. Linearity of $\log$ fluorescence intensity was checked with Immuno-Brite fluorescent beads. FL1 was compensated for spectral overlap by $6 \%$ of the FL2 signal. FL2 was compensated by $19 \%$ of FL1, and FL3 was compensated by $10 \%$ of FL1 and $35 \%$ of FL2. The mean intensity of fluorescence, which is measured on a four-decade logarithmic scale, was converted to a linear scale, using a 256-channel histogram, to give a mean channel number, also known as mean channel fluorescence (MCF), that is, the estimate of the average fluorescence emission of the cells reactive with a specific mAb.

Leukocytes were initially selected for fluorescence analysis by a combination of right-angle and low-angle forward light scatter properties. Two-color fluorescence, with PE-conjugated anti-CD14 as a qualifier, was used to identify specifically monocytes. At least 2,500 monocytes were analyzed in each sample. Fluorescence data from isotype controls were subtracted from data obtained with all reported antibodies.

Phagocytosis and oxidative burst. Staphylococcus aureus strain 25923 from the American Type Culture Collection was stained with Texas Red (Molecular Probes, Eugene, OR) and used in a previously described flow cytometric assay to enumerate monocytes capable of phagocytosing bacteria (3). ROI production was also measured by flow cytometry in blood samples to which 5- (and -6)-dichlorodihydrofluorescein diacetate (DCFDA; catalogue No. C400; Molecular Probes), had been added. This nonfluorescent dye is taken up by leukocytes and converted to a fluorescent derivative when exposed to ROIs in the cytoplasm. Controls included blood without added DCFDA or labeled bacteria and blood preincubated with DCFDA, but no bacteria. After these treatments, PE-conjugated anti-CD14 was added to identify specifically monocytes.

Neopterin assay. Plasma samples frozen at $-70^{\circ} \mathrm{C}$ and not thawed previously were assayed for neopterin by the IMMUtest Neopterin radioimmunoassay kit (DRG International, Inc., Mountainside, NJ) using $0.05 \mathrm{ml}$ of plasma rather than $0.02 \mathrm{ml}$ for increased sensitivity. 
Measurement of complement components and immune complexes in plasma. Soluble immune complexes were measured by ELISA designed to replace the classic Clq binding and Raji cell assays (Quidel, San Diego, CA). The surrogate $\mathrm{Clq}$ binding test measures the quantity of IgG that is associated with $\mathrm{Clq}$ when captured by specific anti-Clq antibodies bound to microtiter plates. The surrogate Raji cell assay measures IgG associated with $\mathrm{iC} 3 \mathrm{~b}, \mathrm{C} 3 \mathrm{~d}$, and $\mathrm{C} 3 \mathrm{~g}$ when these fragments are captured in microtiter plates by anti-C3 antibodies. Total hemolytic complement $\left(\mathrm{CH}_{50}\right)$ was estimated by the method of Kent and Fife (21) as described in the Manual of Clinical Laboratory Immunology (22). Concentrations of complement fragments $\mathrm{Bb}$ and $\mathrm{iC} 3 \mathrm{~b}$, indicative of activation of the alternative and the classic pathways, respectively, were assayed by ELISA (Quidel, Inc). As positive controls, we measured the quantity of $\mathrm{Bb}$ released in vitro after zymosan activation and the quantity of $\mathrm{iC} 3 \mathrm{~b}$ released as a result of activation with aggregated IgG. Plasma, anticoagulated with EDTA and stored at $-70^{\circ} \mathrm{C}$, was thawed, recalcified, and immediately diluted 1:1 with zymosan, or with aggregated IgG, to a final concentration of $1 \mathrm{mg} / \mathrm{ml}$. An aliquot diluted 1:1 with veronal-buffered saline provided a baseline reading. Treated samples were incubated in a shaking water bath at $37^{\circ} \mathrm{C}$ for $30 \mathrm{~min}$. Reactions were stopped by placing the tubes on ice. Supernatants were separated by centrifugation at $15,000 \mathrm{~g}$ for $5 \mathrm{~min}$ at $4^{\circ} \mathrm{C}$ and then diluted between 1:50 and 1:200 in PBS containing 0.01\% thimerosal and 0.05\% Tween 20. 100- $\mu \mathrm{l}$ aliquots of these dilutions were dispensed in triplicate to wells of a 96-well microtiter plate that had been precoated with a mouse mAb to the relevant human complement fragment and then blocked with HSA to prevent nonspecific binding of plasma proteins. $\mathrm{Bb}$ or fragments of $\mathrm{C} 3$ were detected per the manufacturer's instructions.

Treatment of leukocytes with soluble immune complexes or with leukocyte subcellular particles. Fc OxyBURST (Molecular Probes), an antigen-antibody complex created by allowing rabbit antibodies to BSA to react at equivalence with BSA covalently labeled with dichlorodihydrofluorescein, was added at a concentration of $2 \mu \mathrm{g}$ of complex per $100 \mu \mathrm{l}$ of heparinized whole blood, a concentration chosen to activate ROI production maximally. Phagocytosis and internalization of the $\mathrm{Fc}$ OxyBURST by leukocytes results in oxidation of the colorless dichlorodihydrofluorescein to the fluorescent dichlorofluorescein, just as DCFDA, previously described, becomes fluorescent when oxidized.

Subcellular particulates were obtained from co-cultures of MNLs from three unrelated donors, cultured together in the absence of detectable endotoxin (Limulus amebocyte assay) for 3-8 d in Iscove's medium supplemented with L-glutamine (Gibco Laboratories) and $10 \%$ FBS (Hyclone, Logan, UT). The 500- $g$ cell-free supernatants of these cultures were centrifuged at $15,000 \mathrm{~g}$ for $15 \mathrm{~min}$. The pellets obtained were washed, resuspended in fresh Iscove's medium containing $10 \%$ FCS, and immediately added to whole blood as described in Results.

Endothelial adherence and transmigration. Assays were performed as previously reported (15), using bovine aortic endothelial cells (obtained from Dr. Karen Frasier-Scott, University of Houston, Clear Lake, TX) cultured on 3-mm-thick pads of 50\% collagen (Vitrogen, Celtrix, Palo Alto, CA). MNLs $\left(0.5 \times 10^{5}\right)$ were added to the apical surface of unstimulated endothelium and to endothelial monolayers previously stimulated for $16 \mathrm{~h}$ with $10 \mathrm{ng} / \mathrm{ml} E$. coli LPS. Nonadherent leukocytes were removed after a 2 -h incubation at $37^{\circ} \mathrm{C}$ by gently washing the monolayer four times with warm medium. By adding $0.5 \mathrm{ml}$ of $1 \times$ trypsin for $4 \mathrm{~min}$ at $37^{\circ} \mathrm{C}$ and washing the monolayer two times, we then stripped off any leukocytes that adhered to the apical surface of the endothelium. Leukocytes that were still associated with the endothelium after this treatment and those that had migrated into the collagen were recovered by digesting the trypsin-resistant collagen pad with $0.1 \%$ collagenase (Sigma Chemical Co.). MNLs recovered with the dissolved collagen were incubated with specific fluorochrome-conjugated mAbs and enumerated by flow cytometry. LeucoGATE (Becton Dickinson) a mixture of FITC-anti-CD45 and PE-anti-CD14, was used to discriminate monocytes from lymphocytes. MNLs had to be identified positively with a labeled $\mathrm{mAb}$ to distinguish them from the endothelial cells that remained in the trypsin-resistant fraction after collagenase digestion.

Statistics. Descriptive statistics included the arithmetic mean and standard deviation. Because many variables were not normally distributed, a nonparametric method (Kruskal-Wallis one-way ANOVA corrected for ties) was used to assess some group differences. Pairwise comparisons were done using Scheffe's test with a significance level of 5\%. Analyses were conducted on SPSS (SPSS, Inc., Chicago, IL).

\section{Results}

Distinctive phenotypic characteristics of monocytes from stage $A$ as compared with stage B/C HIV-infected patients. Counts of $\mathrm{CD}^{+} \mathrm{T}$ cells were significantly increased in stage A patients' samples, both when compared with the numbers found in controls, and in stage B/C patients' blood; in the latter, the numbers of $\mathrm{CD}^{+} \mathrm{T}$ cells were greatly reduced, approximating those seen in controls (Table I). CD8 ${ }^{+}$TCR $\alpha / \beta^{+}$cells were largely responsible for the increased numbers of $T$ cells in the stage $A$ patients. The numbers of TCR $\gamma / \delta^{+} \mathrm{T}$ cells were decreased in stage $\mathrm{B} / \mathrm{C}$ patients. $\mathrm{CD} 19^{+} \mathrm{B}$ cells appeared to be more abundant in the early and $\mathrm{CD}^{+} 6^{+}$natural killer (NK) cells least abundant in the late stage patients, but these differences were not statistically significant. The numbers of $\mathrm{CD} 14^{+}$monocytes were somewhat reduced in all categories of patients, but there were no significant differences in the numbers of monocytes in blood samples from early and late stage patients (Table I). Plasma samples from 1 of 6 stage A patients contained HIV-1 p24 antigen when tested both with and without acidification; 10 of 19 stage B/C patients' plasma contained p24, when tested without acidification; 2 additional stage B/C patients' plasma samples revealed p24 antigen only when acidified, suggesting that in these two, all of the p24 antigen was incorporated in immune complexes (data not shown).

In the HIV-infected subjects, the percentage of monocytes expressing cell surface molecules that mediate adhesive interactions with bacteria and endothelial cells was significantly altered, but different abnormalities were seen in the early and late stage patients (Table II). For example, in the patients the percentage of monocytes expressing the L16 activation epitope of CD11a/CD18 was significantly increased, especially among stage A patients (Table II, $A$ ). The frequency of monocytes expressing HLA-DP and HLA-DQ was also significantly increased in stage A patients, but in stage $B / C$ patients, the frequency of HLA-DR ${ }^{+}$and $-\mathrm{DQ}^{+}$cells fell toward normal levels. Analysis of CD49d (VLA-4) expression by the nonparametric Kruskal-Wallis test suggested that there were significant differences in the percentages of positive monocytes in the patients and controls, the highest frequency appearing among cells of stage A patients. However, specific pairwise comparison of the frequency of VLA-4 among monocytes from patients and control donors did not reveal statistically significant differences.

The percentage of monocytes expressing CD49e (VLA-5) and CD62L ( $\mathrm{L}$-selectin) as well as the abundance of these cell surface molecules, as estimated from MCF measurements, was significantly decreased in late stage patients (Table II, $B$ and $C)$. The frequencies of monocytes expressing CD29, CD18, CD11a, CD54 (ICAM-1), CD58 (LFA-3), CD31 (PECAM1 ), and HLA-I also appeared to be significantly different among patients and the controls, as assessed by the nonparametric Kruskal-Wallis test $(P \leq .05$; Table II $B)$. But with the exception of CD31, specific pairwise comparisons of the frequency of these antigens in the two patient groups or between either patient group and the controls showed no significant differences (see Table II $B$ and Methods). 
Table I. Peripheral Blood Values in Controls and HIV-1+ Patients with Early and Late Stage Disease

\begin{tabular}{|c|c|c|c|c|c|c|c|}
\hline Parameters & Controls & Stage A & Stage $B / C$ & $P$ value & A vs $\mathrm{C}$ & $\mathrm{B} / \mathrm{C}$ vs $\mathrm{C}$ & $A$ vs $B / C$ \\
\hline $\mathrm{T}$ cells & $1,042 \pm 204(8)$ & $1,696 \pm 516(6)$ & $651 \pm 419$ & $\leq 0.01$ & $*$ & NS & $*$ \\
\hline $\mathrm{CD}^{+} \mathrm{T}$ cells & $708 \pm 249(8)$ & $642 \pm 291(6)$ & $89 \pm 81(19)$ & $\leq 0.0001$ & NS & * & $*$ \\
\hline $\mathrm{CD}^{+} \mathrm{T}$ cells & $389 \pm 121(8)$ & $913 \pm 206(6)$ & $655 \pm 357(18)$ & $\leq 0.0001$ & * & NS & NS \\
\hline $\mathrm{CD} 4 / \mathrm{CD} 8$ ratio & $2.0 \pm 1.3(9)$ & $0.7 \pm .2(6)$ & $0.1 \pm .1(19)$ & $\leq 0.0001$ & * & $*$ & NS \\
\hline $\mathrm{TCR} \alpha / \beta^{+} \mathrm{T}$ cells & $951 \pm 192(8)$ & $1,742 \pm 596(4)$ & $561 \pm 397(15)$ & $\leq 0.005$ & $*$ & NS & $*$ \\
\hline TCG $\gamma / \delta^{+} \mathrm{T}$ cells & $91 \pm 86(8)$ & $94 \pm 45(3)$ & $39 \pm 21(15)$ & $\leq 0.01$ & NS & NS & $*$ \\
\hline $\mathrm{B}$ cells & $137 \pm 75(8)$ & $222 \pm 151$ & $83 \pm 59(19)$ & NS & NS & NS & NS \\
\hline NK cells & $206 \pm 114(8)$ & $182 \pm 147(4)$ & $114 \pm 167(19)$ & NS & NS & NS & NS \\
\hline Monocytes & $768 \pm 400(8)$ & $399 \pm 336(6)$ & $381 \pm 447$ (19) & $\leq 0.05$ & NS & NS & NS \\
\hline
\end{tabular}

Patients were grouped by CDC classification into stage A (early disease) and stage B/C (late disease). Results are the numbers of peripheral blood cells in each subset based on the total white blood cell count (determined by Coulter counter), differential counts from stained blood smears, and, when applicable, immunofluorescence with specific mAbs. Total T cells were defined by the CD3 marker, B cells by CD19, NK cells by CD57, and TCD $\alpha / \beta$ and $\gamma / \delta \mathrm{T}$ cell subsets by specific mAbs. Values presented are the mean \pm SD for the total number of cells per $\mathrm{mm}^{3}$, excepting the CD4/CD8 ratio, which is calculated from the total CD4 and CD8 counts for each individual. The number of subjects for each determination is indicated in parentheses. The $P$ value represents the probability, estimated by the Kruskal-Wallis test, that the means could differ by the observed amounts if all groups were sampled from populations with identical means and standard deviations. The last three columns are pairwise comparisons of stage A versus controls $(A$ vs $C$ ), stage B/C versus controls $(B / C$ vs $C)$, and stage A versus stage B/C $(A$ vs $B / C)$ using Scheffe's test. Because Scheffe's test assumes normally distributed data, it may not provide as powerful an estimate of statistical significance as the Kruskal-Wallis test. * Significance at the 5\% level. NS, not significant.

There were no significant differences in the frequency of monocytes expressing CD11b/CD18 (CR3) and CD11c/CD18 (CR4) in the blood from patients and controls, but these integrins were significantly more abundant, as estimated from $\mathrm{MCF}$ measurements, on the surfaces of monocytes from HIV-infected subjects, especially the stage $\mathrm{B} / \mathrm{C}$ patients (Table II $D$ ). The percentage of monocytes expressing Fc $\gamma$ RIII was slightly increased in early $(23.7 \pm 21.2 \%)$ as compared with late $(16.5 \pm 14.3 \%)$ stage patients or controls $(9.3 \pm 11.1 \%)$, but these differences were not statistically significant. Similarly, there were no significant differences in the percentage of monocytes expressing Fc $\gamma$ RI or Fc $\gamma$ RII (data not shown).

Serial studies showed some variation in monocyte cell surface expression of L16, VLA-4, and L-selectin in selected patients (Fig. 1); but in general, values that were initially outside the normal range remained so over the $10 \pm 2$ mo between measurements.

The selectivity of these alterations in monocyte cell surface antigen expression was documented by the fact that the percentages of cells expressing CDs 4, 15, 34, 35, 36, 41, 44, 45, 49b, 61 , and HLA-DR and the average abundance of these molecules on the monocyte surface as estimated by MCF were not significantly different among patients and controls (data not shown, but available in appendices archived with the editors).

Monocyte phagocytic activity, production of ROIs, and transendothelial migration. Previously, we had observed that the fraction of monocytes in the blood of stage A patients that can phagocytose bacteria and produce ROIs is undiminished or, in some cases, significantly increased as compared with monocytes from uninfected controls (3). Using the same reagents and flow cytometric methods to study blood from stage $\mathrm{B} / \mathrm{C}$ patients, we found that the fraction of monocytes that ingest Texas Red-stained $S$. aureus was significantly decreased. Specifically $59 \pm 13 \%$ of monocytes from patients were effective phagocytes versus $72 \pm 10 \%$ of those from controls $(P=0.03$, $t$ test). However, $67 \pm 21 \%$ of the stage $\mathrm{B} / \mathrm{C}$ patients' phagocytic monocytes as compared with $68 \pm 14 \%$ of control donors' phagocytic monocytes produced ROIs, and the quantities of DCFDA converted to a fluorescent oxidation product were similar in the phagocytes of patients and control donors: The MCF for oxidized DCFDA in the cells of stage $B / C$ patients was $89 \pm 5$ as compared with $90 \pm 14$ for the controls. Thus, although the fraction of monocytes able to phagocytose bacteria was reduced in stage $\mathrm{B} / \mathrm{C}$ patients, the phagocytes that preserved this function retained a normal capacity to generate ROIs.

Production of ROIs was demonstrated in monocytes from $55 \%$ of the stage $\mathrm{B} / \mathrm{C}$ patients immediately after addition of DCFDA to the freshly drawn heparinized whole blood, suggesting that these monocytes had been activated while still resident in the patients' circulation. Spontaneous release of ROIs, detectable immediately after addition of DCFDA, was measured in $<15 \%$ of control donor monocytes in two sets of experiments (see Fig. 2 and Table VI). The percentage of blood monocytes that spontaneously released ROIs correlated inversely with the fraction that ingested the Texas Red-labeled bacteria (Fig. 2), suggesting that the stimuli that induced intracytoplasmic release of reactive oxygen might also have been responsible for the diminished phagocytic capacity of the stage $\mathrm{B} / \mathrm{C}$ patients' monocytes.

Correlations between cell surface phenotype and phagocytic function. Phagocytosis of $S$. aureus correlated directly with monocyte cell surface expression of CD49e (VLA-5) (Fig. 3 C) and reciprocally with cell surface expression of CR3 (CD11b/ CD18) (Fig. $3 A$ ) and CR4 (CD11c/CD18) (Fig. 3 B). Expression of the L16 activation epitope of LFA-1, however, bore no relationship to the capacity of these cells to phagocytose bacteria (data not shown).

Further evidence that the monocytes and/or the fixed tissue macrophages of late stage patients may be activated in vivo came from measurement of plasma neopterin levels. We found $22.8 \pm 10.5 \mathrm{nM} /$ liter neopterin in the plasma of the late stage patients (stage $\mathrm{B} / \mathrm{C}$ ) as compared with $6.7 \pm 1.8 \mathrm{nM} /$ liter in plasma of stage A patients and $4.7 \pm 2.4 \mathrm{nM} /$ liter in plasma from normal controls $(P<.001)$. 
Table II. Phenotype Changes in Peripheral Blood Monocytes from Patients and Controls

\begin{tabular}{|c|c|c|c|c|c|c|c|c|}
\hline Antigen & $\mathrm{CD} \#$ & Controls & Stage A & Stages B and C & $P$ value & $A$ vs $C$ & $\mathrm{~B} / \mathrm{C}$ vs $\mathrm{C}$ & $A$ vs $B / C$ \\
\hline \multicolumn{9}{|c|}{$\begin{array}{l}\text { A. Percentage of monocytes expressing antigens that } \\
\text { are most altered in stage } A\end{array}$} \\
\hline L16 & $11 a^{*}$ & $9 \pm 8$ & $58 \pm 24$ & $37 \pm 27$ & $\leq 0.001$ & $\ddagger$ & $\ddagger$ & NS \\
\hline HLA-DP & & $25 \pm 6$ & $61 \pm 13$ & $37 \pm 19$ & $\leq 0.005$ & $\neq$ & NS & $\ddagger$ \\
\hline HLA-DQ & & $11 \pm 7$ & $42 \pm 19$ & $16 \pm 11$ & $\leq 0.05$ & $\neq$ & NS & $\neq$ \\
\hline VLA-4 & $49 d$ & $52 \pm 11$ & $66 \pm 12$ & $44 \pm 23$ & $\leq 0.05$ & NS & NS & NS \\
\hline \multicolumn{9}{|c|}{$\begin{array}{l}\text { B. Percentage of monocytes expressing antigens that } \\
\text { are most altered in stages B and C }\end{array}$} \\
\hline$\beta 1$ & 29 & $95 \pm 3$ & $93 \pm 4$ & $88 \pm 8$ & $\leq 0.05$ & NS & NS & NS \\
\hline VLA-5 & $49 e$ & $93 \pm 4$ & $81 \pm 9$ & $76 \pm 15$ & $\leq 0.001$ & NS & $\neq$ & NS \\
\hline$\beta 2$ & 18 & $95 \pm 5$ & $91 \pm 8$ & $86 \pm 11$ & $\leq 0.05$ & NS & NS & NS \\
\hline LFA-1 & $11 \mathrm{a}$ & $95 \pm 3$ & $93 \pm 4$ & $89 \pm 8$ & $\leq 0.05$ & NS & NS & NS \\
\hline L-Selectin & $62 \mathrm{~L}$ & $92 \pm 3$ & $85 \pm 8$ & $77 \pm 10$ & $\leq 0.001$ & NS & $\neq$ & NS \\
\hline ICAM-1 & 54 & $94 \pm 4$ & $92 \pm 5$ & $79 \pm 22$ & $\leq 0.005$ & NS & NS & NS \\
\hline LFA-3 & 58 & $89 \pm 11$ & $84 \pm 12$ & $74 \pm 21$ & $\leq 0.05$ & NS & NS & NS \\
\hline PECAM-1 & 31 & $96 \pm 2$ & $93 \pm 4$ & $90 \pm 7$ & $\leq 0.005$ & NS & $\neq$ & NS \\
\hline HLA-I & & $95 \pm 3$ & $93 \pm 2$ & $86 \pm 14$ & $\leq 0.005$ & NS & NS & NS \\
\hline \multicolumn{9}{|c|}{$\begin{array}{l}\text { C. MCF of monocytes positive for antigens changed } \\
\text { most markedly in stages B and C }\end{array}$} \\
\hline VLA-5 & $49 e$ & $121 \pm 7$ & $116 \pm 23$ & $103 \pm 9$ & $\leq 0.001$ & NS & $\neq$ & NS \\
\hline L-Selectin & $62 \mathrm{~L}$ & $140 \pm 9$ & $134 \pm 10$ & $125 \pm 18$ & $\leq 0.05$ & NS & $\neq$ & NS \\
\hline \multicolumn{9}{|c|}{$\begin{array}{l}\text { D. MCF of monocytes positive for antigens changed } \\
\text { in all stages of HIV-infected patients }\end{array}$} \\
\hline MAC-1 & $11 \mathrm{~b}$ & $116 \pm 11$ & $131 \pm 16$ & $130 \pm 14$ & $\leq 0.05$ & NS & $\neq$ & NS \\
\hline $\mathrm{p} 150,95$ & $11 \mathrm{c}$ & $103 \pm 13$ & $112 \pm 11$ & $114 \pm 8$ & $\leq 0.05$ & NS & $\neq$ & NS \\
\hline
\end{tabular}

Peripheral blood MNLs were stained for surface antigens as described in Methods. Results presented are either the percentage of CD14 ${ }^{+}$monocytes positive for the noted marker $(A$ and $B)$ or the MCF of the positive cells $(C$ and $D)$. Data presented are the mean \pm SD. Statistical analyses of data: The $P$ value shown in column 6 reflects the probability, measured by the Kruskal-Wallis test, that the means for the controls, and the stage A versus stage $B / C$ patients could differ by the observed amounts if all groups belonged to a population with identical means and standard deviations. The last three columns show pairwise comparisons of stage $\mathrm{A}$ versus control data $(A v s)$, stage $\mathrm{B} / \mathrm{C}$ versus control data $(B / C$ vs $C)$, and stage $\mathrm{A}$ versus stage B/C $(A v s B / C)$ using Scheffe's test. Because Scheffe's test assumes normally distributed data, it may not provide as powerful an estimate of statistical significance as the Kruskal-Wallis test. * Activation epitope of CD11a. ${ }^{\ddagger}$ Significance at the 5\% level. NS, not significant.

Spontaneous transendothelial migration of monocytes is decreased in the late stages of HIV-1 infection. Previously, we had shown that the ability of monocytes from stage A patients to migrate across confluent endothelial monolayers was unimpaired (15). By contrast, the fraction of stage B/C patients' monocytes that migrated, under standardized conditions, across both unstimulated and LPS-stimulated endothelium was significantly reduced when compared with monocytes from stage A patients and with monocytes from normal controls (Fig. 4).

Immune complexes as likely stimulators for monocyte activation in the late stages of HIV infection. To evaluate whether immune complexes might induce certain of the phenotypic changes observed in the patients' MNLs, we analyzed their cell surfaces for bound IgG. Regardless of CDC stage, $68.9 \pm 29.4 \%$ of all HIV-infected patients' CD4 ${ }^{+} \mathrm{T}$ cells, as compared with $11.3 \pm 6.9 \%$ of normal donors' $\mathrm{CD}^{+}{ }^{+} \mathrm{T}$ cells, were coated with human IgG $(P<0.001)$. Similarly, $63.2 \pm 36.4 \%$ of patients' as compared with $34.8 \pm 19.9 \%$ of the normal donors' $\mathrm{CD}^{+} \mathrm{T}$ cells $(P<0.05)$ displayed IgG. These results suggested either that antigens on the $T$ cell surface may have bound anti-lymphocyte antibodies or that immune complexes, scavenged from the plasma, might have bound to these cells' Fc and/or complement receptors. While the percentages of patients' and control donors' monocytes displaying cell surface IgG were not different, we found in $75 \%$ of the patients that the monocytes had gp120 on their surfaces. The gp120-specific mAb (1536) used in these studies cannot bind to gp120 that is already complexed with CD4 (20). Thus the gp120 found on patients' monocytes is likely to be gp120 incorporated in antigen-antibody complexes that have associated with Fc receptors on the monocyte surface.

In the patients' plasma samples, we found Clq-IgG immune complexes to be especially abundant in stage $\mathrm{B} / \mathrm{C}$ as compared with stage A patients and normal control plasma; however, C3-IgG complexes were only marginally increased (Table III).

Total hemolytic complement and C3 degradation products. Total hemolytic complement levels as estimated from the $\mathrm{CH}_{50}$ as well as the measurement of $\mathrm{C} 3$ degradation products, by means of the ELISA for C3bi, suggested that turnover of circulating complement was abnormally high in both early (stage A) and late (stage B/C) patients. This impression was reinforced by measuring C3bi levels after adding aggregated IgG to convert all available $\mathrm{C} 3$ to $\mathrm{C} 3 \mathrm{bi}$. The results of the latter test suggest that reduced synthesis of complement cannot account 


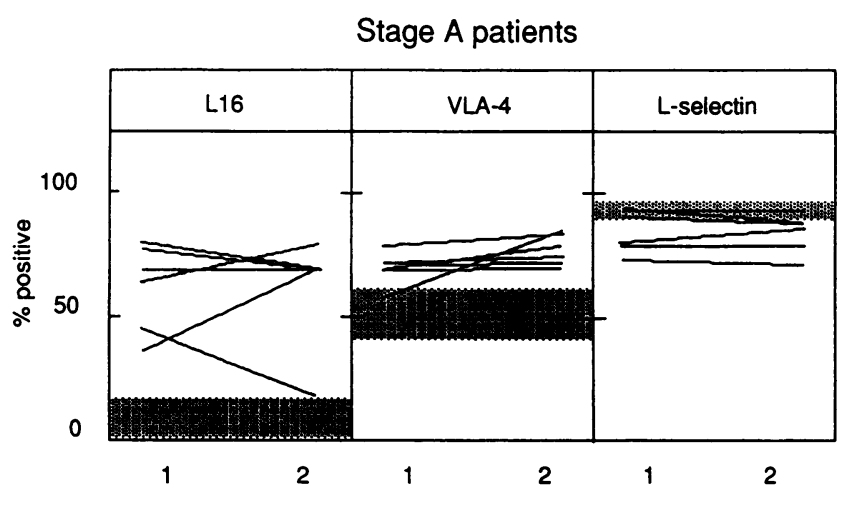

Stage B /C patients

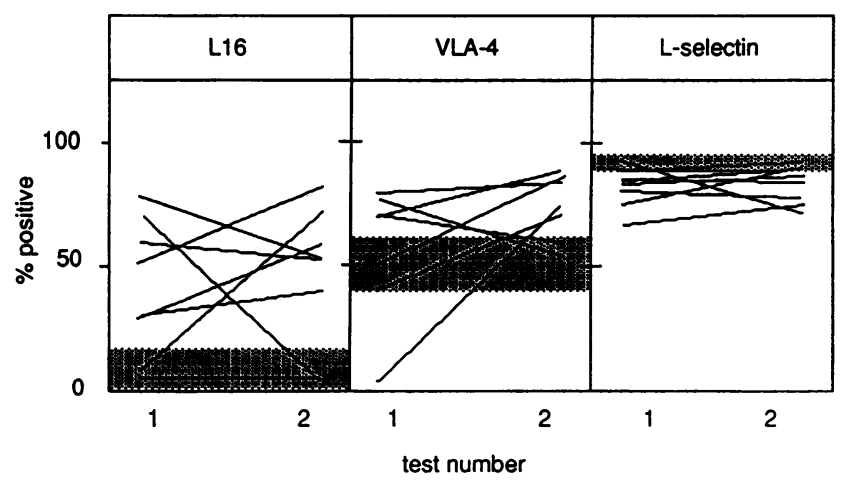

Figure 1. Variation in the percentage of $\mathrm{CD} 4^{+}$monocytes that display the L16 activation epitope of LFA-1, CD62L (L-selectin), and CD49d (VLA-4) markers over time. Each line represents the values from a single individual at the time of enrollment in the study (test 1) and at the second sampling (test 2 ), which occurred $\sim 10$ mo later $(10 \pm 2$ mo). The shaded areas represent the normal range (mean $\pm 1 \mathrm{SD}$ ) for each monocyte marker from a group of 10 controls.

for the low $\mathrm{CH}_{50}$ values found in the patients' plasma. Rather, these low values may be indicative of accelerated complement catabolism, a process that was, if anything, more active in the asymptomatic stage A patients, as suggested by their plasma C3bi levels (Table III).

Effects of immune complexes on monocyte phagocytic activity. Heparinized whole blood samples from healthy normal donors were stimulated with Fc OxyBURST; this stimulation induced the phenotypic and functional abnormalities seen in circulating monocytes of late stage HIV-infected patients (Table IV). After addition of these immune complexes, $>80 \%$ of the monocytes produced reactive oxygen. There was a concomitant reduction in their ability to phagocytose bacteria and a significant increase in cell surface expression of CD11b and CD11c, together with a $>50 \%$ reduction in the number expressing $\mathrm{L}$ selectin and a $38 \%$ reduction in the number expressing VLA-5 (Table IV). However, there was no significant change in the percentage of cells expressing the L16 activation epitope of LFA-1. Stimulation of blood monocytes previously loaded with DCFDA with heat-aggregated human IgG, as an alternative surrogate immune complex, essentially duplicated the results shown in Table IV.

Effect of incubating monocytes with subcellular particles from apoptotic leukocytes. We postulated that, in HIV-infected

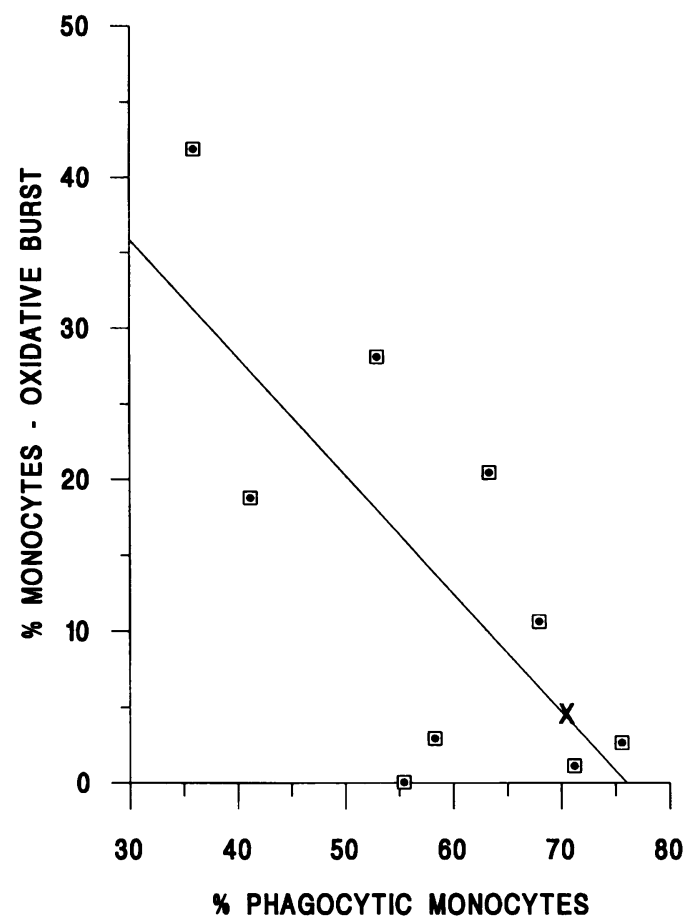

Figure 2. Comparison of the phagocytic ability of stage B/C patients' blood monocytes and their propensity to generate ROIs immediately upon removal from the circulation. Paired samples of leukocytes in whole blood were loaded with DCFDA and incubated in the presence or the absence of Texas Red-labeled $S$. aureus to measure their ability to generate ROIs with and without the stimulus provided by phagocytosis of the bacteria. The percentage of $\mathrm{CD}_{1} 4^{+}$monocytes that generated ROIs without stimulation was plotted against the percentage of monocytes that phagocytosed $S$. aureus. The assessment of the relation between these measurements gave an $r$ value of $-0.72(P<0.02)$. The mean of measurements from 10 control donors is represented by an $\mathrm{X}$. The mean \pm 1 SD for the unstimulated oxidative burst was $5.05 \pm 4$ for controls and $20.39 \pm 24$ for the patients.

individuals, release of subcellular debris from leukocytes undergoing apoptosis might stimulate phenotypic changes observed in circulating monocytes, early in the course of HIV infection. To test this hypothesis, we exposed heparinized normal donor blood samples to subcellular particles, harvested at 15,000 g, from the supernatants of mixed leukocyte cultures. Ultrastructural studies of phagosomes of monocytes obtained from blood that had been exposed to these subcellular particles (Fig. 5) showed that they contained nuclei with condensed chromatin, swollen but intact mitochondria, and sealed vesicles, consistent with the notion that the subcellular particles had been ingested by these phagocytes.

Incubation with the subcellular particles for $90 \mathrm{~min}$ at $37^{\circ} \mathrm{C}$ stimulated expression of L16 in nearly $40 \%$ of normal donor monocytes. However, incubation with freshly isolated intact allogeneic or autologous mononuclear cells or with freshly isolated mononuclear cells that had been killed by pulsed ultrasound, repeated cycles of freezing and thawing, or heat $(2 \mathrm{~h}$ at $42^{\circ} \mathrm{C}$ ) had no effect on monocyte L16 expression, even when the stimulatory cells were opsonized with mAbs specific for HLA-DR or CD3 (Table V).

In addition to stimulating cell surface expression of L16, the subcellular particulates induced other monocyte phenotypic 

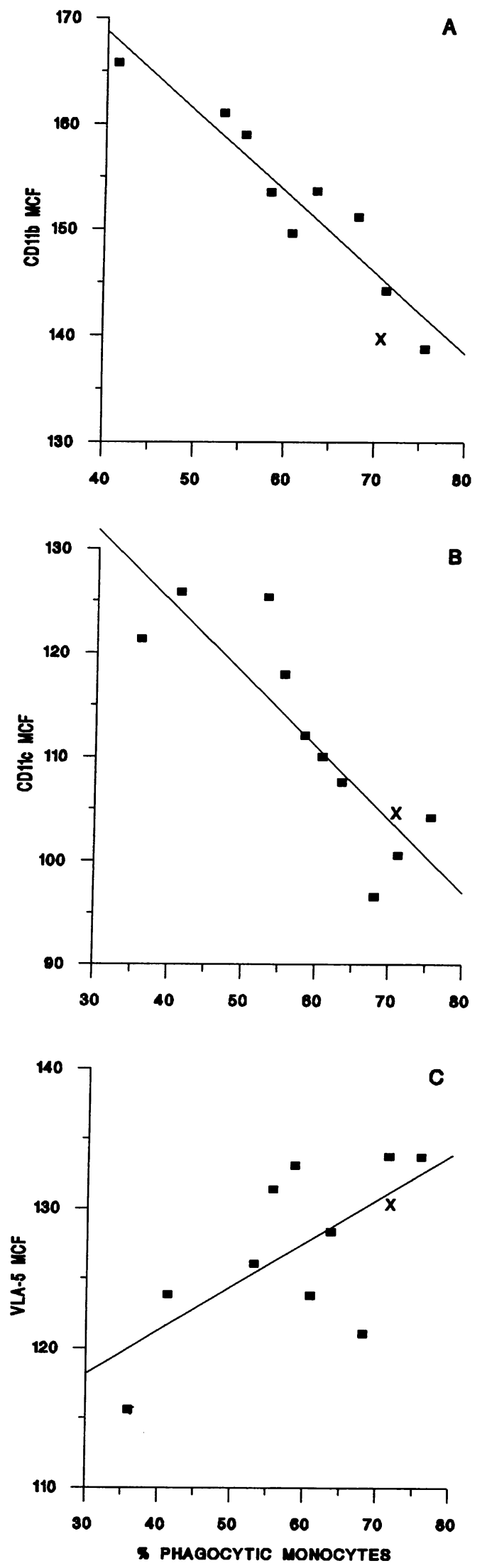

Figure 3. Correlation of surface markers with the ability of patients' monocytes to phagocytose Texas Red-labeled $S$. aureus. Leukocytes in blood were incubated with bacteria at a 10:1 bacteria/leukocyte ratio

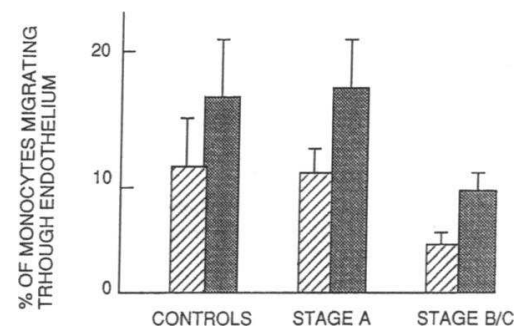

Figure 4. A significantly smaller percentage of monocytes from stage B/ $\mathrm{C}$ patients as compared with monocytes from normal controls migrate across confluent endothelial monolayers $(P$ $\leq 0.03, t$ test $)$. Migration of patients' mono-

cytes was defective across both unstimulated endothelium (striped bars) and LPS-stimulated endothelium (stippled bars).

changes seen in HIV-infected patients (Table VI). These included increased cell surface expression of CD11b and CD11c and a decrease in the percentage of cells expressing L-selectin. There was also a slight decrease in the percentage of cells expressing VLA-5, but the change in cell surface VLA-5 was considerably less than that seen after stimulation with immune complexes (compare data in Tables IV and VI). In addition, stimulation with either LPS or subcellular particles induced about a threefold increase in the numbers of cells that released ROIs intracellularly (Table VI). This suggested that the oxidative burst might have been stimulated by phagocytosis of these particles.

Opposing effects of stimulation with immune complexes and subcellular debris upon the ability of mononuclear cells to migrate across endothelial monolayers. Incubation with subcellular debris under conditions that induced monocyte cell surface expression of L16 and other phenotypic changes documented in Table VI enhanced the capacity of blood monocytes to traverse a monolayer of human umbilical vein endothelial cells, whereas stimulation with immune complexes under conditions that reduced monocyte phagocytic activity and decreased expression of L-selectin and VLA-5, as shown in Table IV, impaired this behavior (Table VII).

Effects of bacterial products on monocyte cell surface phenotype and function. Stimulation of heparinized whole blood with LPS induced phenotypic and functional changes in monocytes that were intermediate between those caused by immune complexes and those caused by subcellular particulates from apoptotic lymphocytes. Addition of LPS caused a dose-dependent increase in the percentage of monocytes expressing the L16 activation epitope of LFA-1; maximum expression of L16 occurred after $90 \mathrm{~min}$ of incubation at doses $\geq 1 \mu \mathrm{g} / \mathrm{ml}$ (Fig. $6)$. However, the ability of cells stimulated with LPS to migrate

for $100 \mathrm{~min}$. Other blood samples were processed for immunofluorescence as described in Methods. The percentage of $\mathrm{CD} 14^{+}$monocytes ingesting bacteria was plotted against the MCF of CD11b $(A, n=9)$, the MCF of CD11c $(B, n=10)$, and the MCF of VLA-5 $(C, n=10)$. Lines represent regression curves for patient values in each plot, and the appropriate $r$ values are -0.95 for $A(P<0.0001),-0.86$ for $B$ $(P<0.001)$, and 0.65 for $C(P<0.05)$. The means of values from 10 control individuals are represented by the $X$ in each panel. Mean \pm 1 SD for the percentage of phagocytic cells was $72 \pm 14$ for controls and $58 \pm 4$ for patients; for CD11b these MCF values were $140 \pm 10$ for controls and $153 \pm 8$ for patients; for CD11c these MCF values were $105 \pm 3$ for controls and $112 \pm 3$ for patients; and VLA-5 MCF these values were $131 \pm 2$ for controls and $127 \pm 2$ for patients. 
Table III. Immune Complex Levels, $\mathrm{CH}_{50}$, and Complement Degradation Products

\begin{tabular}{lccccc}
\hline \multicolumn{1}{c}{ Assay } & Controls & Stage A & $P$ value* & Stage B/C & $P$ value $^{\ddagger}$ \\
\hline CIC-Clq $(\mu \mathrm{g} / \mathrm{ml})^{8}$ & $1 \pm 2$ & $3 \pm 2$ & 0.009 & $6 \pm 5$ & 0.0002 \\
CIC-C3 frag $(\mu \mathrm{g} / \mathrm{ml})^{\| 1}$ & $8 \pm 10$ & $13 \pm 10$ & NS & $15 \pm 11$ & NS \\
$\mathrm{CH}_{50}(\mathrm{U})^{\mathrm{r}}$ & $57 \pm 19$ & $31 \pm 20$ & 0.01 & $32 \pm 22$ & 0.0009 \\
iC3b $(\mu \mathrm{g} / \mathrm{ml})^{* *}$ & $6 \pm 7$ & $17 \pm 13$ & 0.02 & $12 \pm 13$ & NS \\
iC3b act. $(\mu \mathrm{g} / \mathrm{ml})^{\ddagger \pm}$ & $407 \pm 106$ & $469 \pm 183$ & NS & $379 \pm 108$ & NS \\
& & & & & \\
\hline
\end{tabular}

Plasma samples from 15 controls, 6 early (stage A) disease, and 19 late (stage $B / C$ ) disease were tested. Data are presented as the mean \pm SD. * Probability that the stage A patients differed from the control group (unpaired Student's $t$ test). ${ }^{\ddagger}$ Probability that the stage B/C patients differed from the control group (unpaired Student's $t$ test). Circulating immune complexes measured as IgG bound to Clq. "Circulating immune complexes measured as IgG complexed with C3. 'Total complement activity. ${ }^{* *}$ Basal levels of C3bi by ELISA. ${ }^{\ddagger \ddagger}$ Levels of C3bi measured by ELISA after in vitro addition of aggregated IgG to recalcified plasma. NS, not significant.

across endothelial monolayers was significantly reduced (data not shown).

To investigate whether exposure to whole bacteria caused similar phenotypic changes, blood samples were incubated with $E$. coli, $S$. pneumoniae, or $S$. aureus. Each of these had been labeled with Texas Red. After phagocytosis of $E$. coli, $46 \%$ of monocytes expressed the L16 epitope of LFA-1, whereas exposure to $S$. pneumoniae caused $11 \%$ of monocytes to express this activation epitope. Stimulation with $S$. aureus, $\geq 1 \mathrm{mg} /$ $\mathrm{ml}$ zymosan, or $\geq 10 \mu \mathrm{M}$ f-MLP caused no increase in L16 expression above baseline.

Effect of proinflammatory cytokines and viral products on monocyte cell surface phenotype. Considering that diverse proinflammatory cytokines and viral gene products may be released into the circulation of infected subjects, we investigated the

Table IV. Effect of Immune Complexes on Monocyte Phagocytosis and Expression of Surface Molecules

\begin{tabular}{|c|c|c|c|}
\hline Parameter & No treatment & Immune complexes & $P$ value* \\
\hline Phagocytosis (\% pos. $)^{\ddagger}$ & $51 \pm 11$ & $6 \pm 3$ & 0.005 \\
\hline CD11b $(\mathrm{MCF})^{8}$ & $111 \pm 10$ & $147 \pm 27$ & 0.02 \\
\hline CD11c (MCF) & $94 \pm 15$ & $109 \pm 12$ & 0.02 \\
\hline L16 (\% pos.) & $11 \pm 14$ & $15 \pm 5$ & NS \\
\hline L-Selectin (\% pos.) & $67 \pm 13$ & $12 \pm 4$ & 0.01 \\
\hline VLA-5 (\% pos.) & $71 \pm 21$ & $33 \pm 20$ & 0.02 \\
\hline Cells taking up IC" & NA & $83 \pm 4$ & \\
\hline
\end{tabular}

Samples of peripheral blood $(100 \mu \mathrm{l})$ from normal donors were incubated for $1 \mathrm{~h}$ at $37^{\circ} \mathrm{C}$ with immune complexes $(2 \mu \mathrm{g}$ of Fc OxyBURST in $2 \mu \mathrm{l}$ ) or $2 \mu \mathrm{l}$ of buffer (No treatment). To measure phagocytosis, Texas Red-labeled $S$. aureus was added to some samples at a 10:1 bacterial/leukocyte ratio for $100 \mathrm{~min}$. Other aliquots of blood were chilled to $4^{\circ} \mathrm{C}$ and stained with mAbs against the indicated surface markers (CD11b, CD11c, L16, L-selectin, and VLA-5) followed by PEconjugated goat anti-mouse Ig. Data are the mean \pm SD for four control donors for phagocytosis and three donors for surface markers. * Significance by Student's $t$ test for paired samples. ${ }^{\ddagger}$ Percentage of all monocytes positive for marker. ${ }^{8} \mathrm{MCF}$ of positive monocytes based on a 256-channel histogram. "Percentage of cells producing reactive oxygen products after uptake of the Fc OxyBURST. IC, immune complexes. NA, not applicable. NS, not significant.

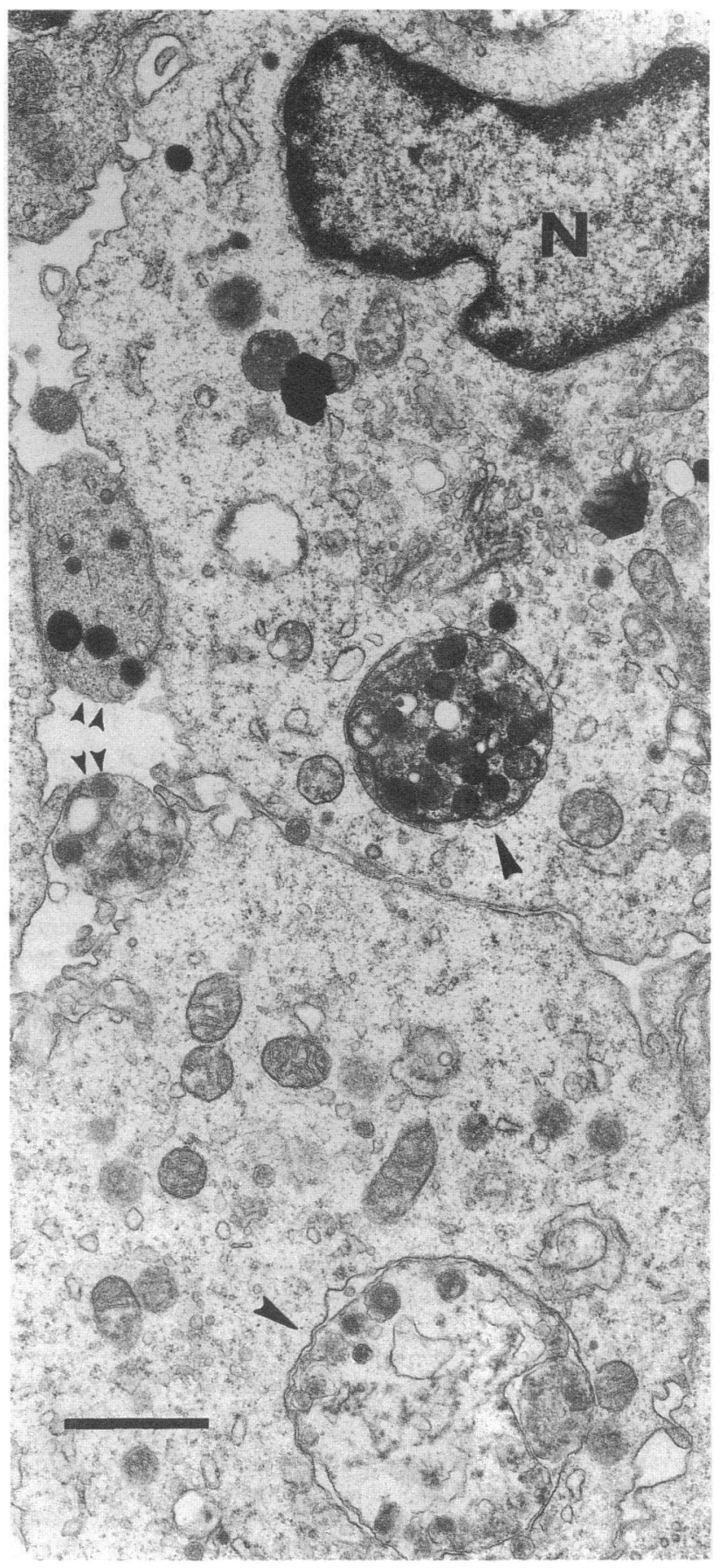

Figure 5. Electron micrograph of monocytes exposed to subcellular particles. A cell preparation enriched for monocytes $\left(2 \times 10^{6}\right)$ was incubated with the $15,000-g$ sediment from the 500- $g$ culture supernatant of $16 \times 10^{6}$ mononuclear cells that had been involved in a threeway mixed leukocyte reaction for $7 \mathrm{~d}$. After a 2-h incubation, the monocytes were fixed in glutaraldehyde and processed for electron microscopy. Apoptotic bodies in phagosomes are marked by single arrows and apoptotic bodies still external to the cells are marked by double arrows. $N$, nucleus. $\times 15,000 \mathrm{Bar}, 1 \mu \mathrm{m}$.

possibility that specific cytokines or proteins encoded by the virus could stimulate the expression of the L16 activation epitope of LFA-1 and other phenotypic changes that we saw in monocytes of HIV-infected subjects. Addition of between 1 and 
Table V. Induction of the L16 Epitope on Normal Donor Monocytes after Incubation with Subcellular Particles but Not after Stimulation with Intact MNLs

\begin{tabular}{lc}
\hline \multicolumn{1}{c}{ Stimulus } & Percentage of monocytes expressing L16 \\
\hline $0.5 \times 10^{6}$ intact MNLs & $1 \pm 9$ \\
$1.0 \times 10^{6}$ intact MNLs & $2 \pm 2$ \\
$2.5 \times 10^{6}$ intact MNLs & $2 \pm 1$ \\
$5.0 \times 10^{6}$ intact MNLs & $3 \pm 2$ \\
Subcellular particles & $56 \pm 1$ \\
\hline
\end{tabular}

Whole blood $(1 \mathrm{ml})$ was treated for $90 \mathrm{~min}$ with varying doses of viable leukocytes ranging from $0.5 \times 10^{6}$ to $5.0 \times 10^{6}$ or with subcellular particles from the culture supernatant of $5 \times 10^{6}$ MNLs stained to identify cells expressing the L16 epitope, and analyzed by flow cytometry. The stimulating leukocytes were $95-97 \%$ viable and $15-23 \%$ $\mathrm{CD}_{14}{ }^{+}$. Results presented are the difference in the numbers of CD14 monocytes expressing L16 in treated and untreated samples. The baseline expression of L16 in untreated blood was $12 \pm 3 \%$. Values listed are the mean $\pm \mathrm{SD}$ of the results obtained with three donors.

$10 \mathrm{ng} / \mathrm{ml}$ recombinant human TNF- $\alpha$, IFN- $\gamma$, IL-4, TGF- $\beta$, PDGF, GM-CSF, and platelet-activating factor to blood from normal donors significantly reduced the percentage of monocytes that expressed L-selectin without affecting the percentage that expressed L16. For example, L-selectin was found on $87 \pm 6 \%$ of unstimulated monocytes and decreased to an average of $70 \pm 13 \%$ after exposure to $1 \mathrm{ng} / \mathrm{ml} \mathrm{TNF}-\alpha$ and to $52 \pm 20 \%$ after exposure to $10 \mathrm{ng} / \mathrm{ml}$ TNF- $\alpha$, whereas the fraction of monocytes expressing L16 was $7 \pm 4 \%$ in untreated blood and remained at $9 \pm 2 \%$ for all doses of TNF- $\alpha$. Treatment with IL$1 \alpha$ or IL- $1 \beta$ within the same dose range had no effect on either L-selectin or L16 expression. Similar decreases in L-selectin expression were observed after incubation with up to $5 \mu \mathrm{g} / \mathrm{ml}$

Table VI. Effect of LPS and Subcellular Particles on Monocyte Phagocytic Activity and Cell Surface Expression of CDI1b, CDIIC, L16, and CD62L

\begin{tabular}{lccccc}
\hline \multicolumn{1}{c}{ Parameter } & No treatment & LPS & $P$ value* & SCP & $P$ value $^{\ddagger}$ \\
\hline Phagocytosis (\% pos.) & $75 \pm 14$ & $79 \pm 14$ & NS & $75 \pm 13$ & NS \\
CD11b (MCF) & $159 \pm 11$ & $181 \pm 7$ & 0.006 & $165 \pm 11$ & 0.002 \\
CD11c (MCF) & $121 \pm 15$ & $114 \pm 7$ & 0.01 & $138 \pm 5$ & 0.02 \\
L16 (\% pos.) & $23 \pm 14$ & $71 \pm 18$ & 0.0002 & $67 \pm 20$ & 0.00002 \\
CD62L (\% pos.) & $81 \pm 13$ & $21 \pm 18$ & 0.001 & $62 \pm 3$ & 0.01 \\
VLA-5 (\% pos.) & $92 \pm 21$ & $92 \pm 2$ & NS & $91 \pm 1$ & 0.02 \\
Oxidative burst (\% pos.) & $15 \pm 9$ & $39 \pm 23$ & 0.007 & $44 \pm 26$ & 0.005
\end{tabular}

Samples of peripheral blood $(100 \mu \mathrm{l})$ from normal donors were incubated for 90 min at $37^{\circ} \mathrm{C}$ with $1 \mu \mathrm{g} / \mathrm{ml}$ LPS or the subcellular particles $(S C P)$ harvested from $4 \times 10^{6} \mathrm{MNLs}$ in a 5-d three-way mixed leukocyte reaction. Some aliquots were then incubated with Texas Red-labeled $S$. aureus to measure phagocytosis; others were chilled to $4^{\circ} \mathrm{C}$ and stained with mAbs to CD11b, CD11 c, L16, L-selectin, or VLA-5, followed by FITC-conjugated anti-mouse mAb. To measure oxidative burst, cells were preloaded with DCFDA before exposure to subcellular particles or LPS. All samples were counterstained with PE-conjugated anti-CD14 to identify monocytes. Data are the mean \pm SD for five donors for surface markers and eight donors for the remaining studies. * The probability that LPS treatment differs from no treatment; Student's $t$ test for paired samples. ${ }^{\ddagger}$ The probability that subcellular particles treatment differs from no treatment; Student's $t$ test for paired samples. "Percentage of $\mathrm{CD}^{+} 4^{+}$monocytes positive for marker. "MCF of positive monocytes based on a 256-channel histogram.

NS, not significant.
Table VII. Effect of Immune Complexes and Subcellular Particles on Monocyte Transendothelial Migration

\begin{tabular}{lcc}
\hline \multicolumn{1}{c}{ Treatment } & Numbers of migrating monocytes & $P$ value* \\
\hline Medium & $2,560 \pm 300$ & \\
Subcellular particles & $3,500 \pm 100$ & 0.006 \\
Fc OxyBURST & $400 \pm 60$ & 0.001 \\
& & \\
\hline
\end{tabular}

Equal numbers of normal donor MNLs were incubated with medium, subcellular particles, or Fc OxyBURST for $1 \mathrm{~h}$ at $37^{\circ} \mathrm{C}$ and then allowed to migrate through confluent monolayers of bovine aortic endothelial cells for $2 \mathrm{~h}$. PE-conjugated anti-CD14 was used to identify the monocytes among the MNLs that migrated through the endothelium to facilitate their enumeration by flow cytometry. The table shows the mean $\pm \mathrm{SD}$ for triplicate determinations. * Statistical analysis ( $t$ test) comparing results of samples treated with subcellular particles or Fc OxyBURST and those treated with tissue culture medium.

recombinant gp120 or gp160, produced in baculovirus-infected cells, or stimulation with the same quantities of recombinant rev or reverse transcriptase, produced in E. coli, but none of these agents induced L16 expression (data not shown). Treatment with $1-30 \mu \mathrm{g} / \mathrm{ml}$ recombinant tat and $\leq 10 \mu \mathrm{g} / \mathrm{ml}$ recombinant p24 also had no effect on monocyte L16 expression (data not shown).

\section{Discussion}

The results of the present studies are consistent with the notion that capture of antigen-antibody complexes by lymphoid tissues decreases significantly during the course of HIV infection $(1,2,13,23-25)$. Excessive numbers of IgG-coated $\mathrm{T}$ cells and gp120-coated monocytes were found at all stages of HIV infection, but high levels of IgG-Clq immune complexes were especially abundant in the late stage patients. Considered together with data suggesting that intravascular complement activation proceeds at a brisk pace even in stage A patients, these results support the idea that lymphoreticular clearance of immune complexes becomes less effective in the late stages of infection (13). This conclusion is also consistent with data

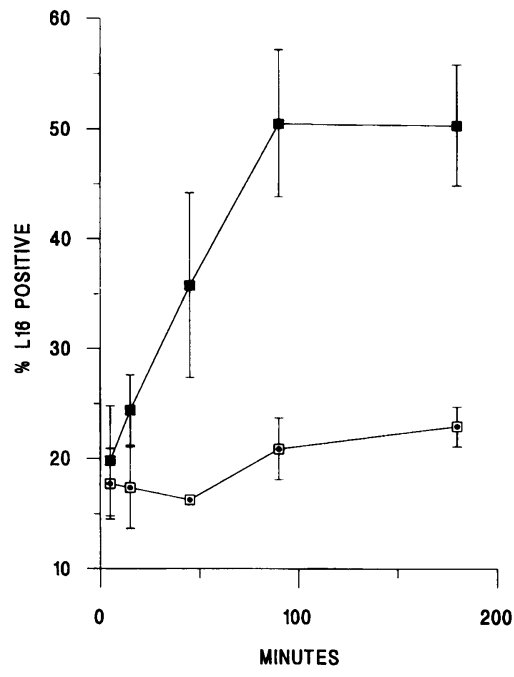

Figure 6. Kinetics of the monocyte response to stimulation with $E$. coli LPS. Whole blood was treated for the indicated times with PBS (lower line) or with $1 \mu \mathrm{g} / \mathrm{ml}$ LPS (upper line), and the $\mathrm{CD} 14^{+}$cells were assessed for display of the L16 epitope of LFA-1. The points represent the mean \pm SEM of data from three different donors. 
showing that sequestration of large quantities of virus, complexed with antibody and complement, in germinal centers is a prominent feature early in HIV-1 infection (2). The disorganization of follicular architecture and decline in numbers of follicles that contain virus-antibody complexes in the late stages of infection $(2,24,25)$ also suggest that the capacity of the lymphoreticular system to remove immune complexes declines as the disease progresses.

A particularly novel feature of this study is the demonstration that monocytes in advanced HIV infection display a distinctive cell surface phenotype that may be representative of monocytes that have been activated to release ROIs. These cells also appear to have reduced ability to migrate across endothelial monolayers and phagocytose bacteria. By stimulating normal donor monocytes with antigen-antibody complexes, formed at equivalence, or aggregated human IgG in vitro we were able to replicate phenotypic and functional abnormalities seen in these late stage patients' monocytes.

Equally novel is the recognition that distinctive characteristics of monocytes from stage A patients, including a normal or enhanced ability to phagocytose bacteria and migrate across endothelial monolayers $(3,15)$, could be replicated in vitro by exposing normal donor monocytes to subcellular particulates released as the result of apoptosis. The augmented phagocytic and antibacterial activities $(3,4)$ that result from stimulation with such subcellular particulates may offset, for a while, the defects in $\mathrm{T}$ cell-mediated immune function that begin to accrue even in the early stages of HIV infection (2).

Our results suggest that at some critical juncture in HIV infection, a qualitative change occurs in the environment of circulating monocytes that modifies their ability to phagocytose bacteria and to emigrate into soft tissues. Consequently, their ability to orchestrate an appropriate host defense against infectious agents declines $(9-12)$. The data reported here are the first, to our knowledge, to provide evidence that monocytes of HIV-infected individuals ultimately develop functional defects reminiscent of those seen in leukocytes of patients with leukocyte adhesion deficiency syndrome, in whom abnormal cell surface expression of key adhesion molecules significantly impairs leukocyte surveillance against soft tissue infection (26).

The present studies suggest that subcellular particulates released from apoptotic leukocytes can signal normal donor monocytes to express the phenotypic and functional properties of monocytes from stage A patients. Spontaneous apoptosis may be one of the agents responsible for loss of both infected and uninfected $T$ cells in HIV-infected individuals $(27,28)$. Cross-linking of cell surface CD4 molecules by gp120, or antibody plus gp120 bound to $\operatorname{CD} 4(29,30)$ as well as products of HIV-1-infected macrophages, such as prostaglandin E2 (31), may induce apoptosis of uninfected autologous lymphocytes. Subcellular components released by apoptotic lymphocytes are thus likely to be abundant in lymphoid tissues (32) and peripheral blood (30) early in the course of HIV infection. Although cells of many lineages can ingest apoptotic cells and their subcellular vesicular debris, monocytes and tissue macrophages are particularly well adapted for this role (33). For example, macrophages can recognize and remove senescent neutrophils before they release their granular contents (33). Whereas mature monocyte-derived macrophages that phagocytose apoptotic neutrophils or lymphocytes via vitronectin receptors do not appear to be activated, as measured by release of thromboxane $\mathrm{B}_{2}$ or the granule enzyme $N$-acetyl- $\beta$-D-glucosam- inidase (34), monocytes that phagocytose apoptotic neutrophils that have been opsonized with immune serum will be activated according to these criteria. Thus, whether or not macrophages become activated appears to depend on the type of receptor used to take up the particulates. In studies of freshly isolated blood monocytes, we have not been able to demonstrate vitronectin receptors by immunofluorescence using mAb against $\alpha v$ (data not shown). Thus it is possible that freshly harvested blood monocytes respond differently from mature monocyte-derived macrophages, or that they use different receptors to phagocytose particulates from apoptotic leukocytes.

Recent studies demonstrating that neoplastic epithelial cells can take up plasma membrane-delimited vesicles shed by leukocytes and subsequently display leukocyte proteins, formerly incorporated in those vesicles, on their cell surfaces (35) raise the possibility that some of the observed changes in monocyte surface protein expression may have resulted from uptake of vesicles from apoptotic leukocytes rather than an increase in endogenous synthesis of these molecules. CD11a/CD18 (LFA1) was among the cell surface proteins passively transferred to epithelial cells by such a mechanism (35); as a result, the epithelial cells developed novel adhesive properties, specifically the ability to bind to ICAM-1 -coated beads and to endothelial cells.

Although incubation of normal donor monocytes in vitro with $E$. coli LPS stimulated L16 expression, we found that LPS stimulation did not replicate all of the phenotypic and functional characteristics of monocytes from stage A patients. For example, LPS stimulation did not reduce the frequency of cells expressing VLA-5, and it suppressed migration of normal donor monocytes across endothelial monolayers (data not shown). In stage A patients, spontaneous migration of monocytes across endothelial monolayers (15) was not decreased. Since there is little evidence that asymptomatic HIV-infected individuals experience frequent episodes of gram-negative bacteremia, we suggest that exposure to products of these bacteria in vivo is not likely to be responsible for the monocyte phenotypic changes seen in stage A patients.

In other studies, immune complexes have also been found on T cells, on monocytes (36), and in cell-free plasma of HIVinfected subjects $(37,38)$ at all stages of the infection (39). In addition, immune complexes have been implicated in the pathophysiology of the thrombocytopenic purpura seen in HIVinfected subjects (40), as agents that can cause $\mathrm{CD} 4^{+} \mathrm{T}$ cell unresponsiveness (41), and as a cause of $\operatorname{IgA}$ nephropathy in HIV-infected patients (42). It has been suggested that complexes incorporating infectious HIV-1 and antibodies to viral gp120 can be taken up by Fc receptors (43) and facilitate infection of monocyte-derived macrophages (44-46). It is not clear, however, that infection depends exclusively on Fc receptormediated uptake of virus-antibody complexes by these cells $(47,48)$. Exposure to circulating immune complexes may also suppress neutrophil bactericidal activity in AIDS patients (49) and, by saturating the available $\mathrm{Fc}$ receptors of fixed tissue phagocytes, may significantly reduce intravascular clearance of opsonized particulates $(13,50)$.

The comparatively low levels of IgG-C1q complexes in sera of stage A patients were evidently not sufficient to depress monocyte phagocytosis and ROI generation (3), possibly because the capacity of the mononuclear phagocyte system to clear circulating immune complexes had not yet been severely compromised. In our experiments (Table IV), addition of $\geq 20$ 
$\mu \mathrm{g} / \mathrm{ml}$ Fc OxyBURST or heat-aggregated human IgG was needed to stimulate significant ROI production and to suppress monocyte phagocytosis of $S$. aureus. Thus both in vivo and in vitro, it would appear that a critical threshold concentration of immune complexes is needed to alter monocyte function.

Data in Fig. $3 C$ emphasize the importance of CD49e/CD29 (VLA-5)-mediated interactions in monocyte phagocytosis of gram-positive bacteria. Reduction in both the cell surface expression and the percentage of monocytes expressing this fibronectin receptor may explain the reduced uptake of $S$. aureus in these experiments $(51,52)$. Signaling induced by uptake of immune complexes may modulate monocyte cell surface expression of VLA-5, since significant loss of VLA-5 in vitro and phagocytic activity (Table IV) followed within $1 \mathrm{~h}$ after stimulation with this reagent.

The data in Table II show distinct abnormalities in cell surface phenotype that discriminate monocytes from stage A as compared with stage $\mathrm{B} / \mathrm{C}$ patients. Previous studies have not identified distinct abnormalities in monocyte cell surface antigens in HIV-infected individuals (53). However, these earlier studies used a less extensive battery of mAb reagents and did not attempt to relate changes in monocyte antibacterial activity to changes in cell surface phenotype.

Monocytes isolated from normal donor blood by various methods, though functionally and phenotypically heterogeneous, are not strictly divisible into specific subpopulations; the functional and phenotypic diversity seen here and in other studies may reflect a continuum of maturational and activation states (54). Although we have stressed the differences seen in monocytes of stage A versus stage $B / C$ patients, we recognize, as the data in Table II illustrate, that the observed differences are not strictly dichotomous. Abnormalities such as the increased cell surface expression of CD11b/CD18 and CD11c/CD18 were seen in all patients. Other abnormalities, such as the increased frequency of cells expressing the L16 activation epitope of LFA-1, though seen predominantly in stage A patients' monocytes, were also seen in some patients with advanced disease (Table II). Thus abnormalities seen predominantly in leukocytes from one or another category of patients may reflect the diversity and heterogeneity of stimuli that affect monocytes of HIV-infected subjects during the prolonged course of this disease.

\section{Acknowledgments}

This work was supported by the Houston VA Medical Center, by the VA Merit Review Program, and by grants from the Department of Health and Human Services (NIH RO1 AI28071, NIH UO1 AI33236, and NIH RO1 NS32583).

\section{References}

1. Pantaleo, G., C. Graziosi, J. F. Demarest, L. Butini, M. Montroni, C. H. Fox, J. M. Orenstein, D. P. Kotler, and A. S. Fauci. 1993. HIV infection is active and progressive in lymphoid tissue during the clinically latent stage of disease. Nature (Lond.). 362:355-358.

2. Pantaleo, G., C. Graziosi, and A. S. Fauci. 1993. The immunopathogenesis of human immunodeficiency virus infection. N. Engl. J. Med. 328:327-335.

3. Bandres, J. C., J. A. Trial, D. M. Musher, and R. D. Rossen. 1993. Increased phagocytosis and reactive oxygen product generation by neutrophils and monocytes of stage 1 HIV-1 infected men. J. Infect. Dis. 168:75-83.

4. Musher, D. M., D. A. Watson, D. Nickeson, F. Gyorkey, C. Lahart, and R. D. Rossen. 1990. The effect of HIV infection on phagocytosis and killing of Staphylococcus aureus by human pulmonary alveolar macrophages. Am. J. Med. Sci. 299:158-163.
5. Nottet, H. S. L. M., L. de Graaf, N. M. de Vos, L. J. Bakker, J. A. G. van Strijp, M. R. Visser, and J. Verhoef. 1993. Phagocytic function of monocytederived macrophages is not affected by human immunodeficiency virus type 1 infection. J. Infect. Dis. 168:84-91.

6. Baldwin, G. C., J. Fleischmann, Y. Chung, Y. Koyanagi, I. S. Chen, and D. W. Golde. 1990. Human immunodeficiency virus causes mononuclear phagocyte dysfunction. Proc. Natl. Acad. Sci. USA. 87:3933-3937.

7. Asjo, B., I. Ivhed, M. Gidlund, S. Fuerstenberg, E. M. Fenyo, K. Nilsson, and H. Wigzell. 1987. Human immunodeficiency virus infection down-regulates HLA class II expression and induces differentiation in promonocytic U937 cells. J. Clin. Invest. 79:1883-1889.

8. Rossen, R. D., C. W. Smith, A. H. Laughter, C. A. Noonan, D. C. Anderson, W. M. McShan, M. Y. Hurvitz, and F. M. Orson. 1989. HIV-1-stimulated expression of CD11/CD18 integrins and ICAM-1: a possible mechanism for extravascular dissemination of HIV-1-infected cells. Trans. Assoc. Am. Phys. 102:117-130.

9. Braun, D. P., H. Kessler, L. Falk, D. Paul, J. E. Harris, B. Blaauw, and A. Landay. 1988. Monocyte functional studies in asymptomatic, human immunodeficiency disease virus (HIV)-infected individuals. J. Clin. Immunol. 8:486-494.

10. Clerici, M., N. I. Stocks, R. A. Zajac, R. N. Boswell, and G. M. Shearer. 1990. Accessory cell function in asymptomatic human immunodeficiency virusinfected patients. Clin. Immunol. Immunopathol. 54:168-173.

11. Wahl, S. M., J. B. Allen, S. Gartner, J. M. Orenstein, M. Popovic, D. E. Chenoweth, L. O. Arthur, W. L. Farrar, and L. M. Wahl. 1989. HIV-1 and its envelope glycoprotein down-regulate chemotactic ligand receptors and chemotactic function of peripheral blood monocytes. J. Immunol. 142:3553-3559.

12. Pos, O., A. Stevenhagen, P. L. Meenhorst, F. P. Kroon, and R. Van Furth. 1992. Impaired phagocytosis of Staphylococcus aureus by granulocytes and monocytes of AIDS patients. Clin. Exp. Immunol. 88:23-28.

13. Bender, B. S., B. L. Davidson, R. Kline, C. Brown, and T. C. Quinn. 1988. Role of the mononuclear phagocyte system in the immunopathogenesis of human immunodeficiency virus infection and the acquired immunodeficiency syndrome. Rev. Infect. Dis. 10:1142-1154.

14. Washburn, R. G., C. U. Tuazon, and J. E. Bennet. 1985. Phagocytic and fungicidal activity of monocytes from patients with acquired immunodeficiency syndrome. J. Infect. Dis. 151:585-586.

15. Birdsall, H. H., J. Trial, J. A. Hallum, A. L. deJong, L. K. Green, J. C. Bandres, S. A. Smole, A. H. Laughter, and R. D. Rossen. 1994. Phenotypic and functional activation of monocytes in HIV-1 infection: interactions with neural cells. J. Leukocyte Biol. 56:310-317.

16. Keizer, G. D., W. Visser, M. Vliem, and C. G. Figdor. 1988. A monoclonal antibody (NKI-L16) directed against a unique epitope on the alpha-chain of human leukocyte function-associated antigen 1 induces homotypic cell-cell interactions. J. Immunol. 140:1393-1400.

17. McIntyre, B. W., E. L. Evans, and J. L. Bednarczyck. 1989. Lymphocyte surface antigen L25 is a member of the integrin receptor superfamily. 264:1374513750

18. Rothlein, R., M. L. Dustin, S. D. Marlin, and T. A. Springer. 1986. A human intercellular adhesion molecule (ICAM-1) distinct from LFA-1. J. Immunol. 137:1270-1274.

19. Kishimoto, T. K., M. A. Jutila, and E. C. Butcher. 1990. Identification of a human peripheral lymph node homing receptor: a rapidly down-regulated adhesion molecule. Proc. Natl. Acad. Sci. USA. 87:2244-2248.

20. Sun, N. C., D. D. Ho, C. R. Sun, R. S. Liou, W. Gordon, M. S. Fung, N. Li, R. C. Ting, T. H. Lee, and N. T. Chang. 1989. Generation and characterization of monoclonal antibody to the putative CD4 binding domain of HIV-1 type 1 gp120. J. Virol. 63:3579-3585.

21. Kent, J. F., and E. H. Fife. 1963. Precise standardization of reagents for complement fixation. Am. J. Trop. Med. 12:103-116.

22. Rose, N. R., E. C. de Macario, J. L. Fahey, H. Friedman, and G. M. Penn, editors. 1992. Manual of Clinical Laboratory Immunology, 4th edition. Am. Soc. Microbiology, Washington, DC

23. Pantaleo, G., C. Graziosi, L. Butini, P. A. Pizzo, S. M. Schnittman, D. P. Kotler, and A. S. Fauci. 1991. Lymphoid organs function as major reservoirs for human immunodeficiency virus. Proc. Natl. Acad. Sci. USA. 88:9838-9842.

24. Fox, C. H., R. K. Tenner, P. Racz, A. Firpo, P. A. Pizzo, and A. S. Fauci 1991. Lymphoid germinal centers are reservoirs of human immunodeficiency virus type 1 RNA. J. Infect. Dis. 164:1051-1057.

25. Pantaleo, G., C. Graziosi, and A. S. Fauci. 1993. The role of lymphoid organs in the pathogenesis of HIV infection. Semin. Immunol. 5:157-163.

26. Anderson, D. C., and T. A. Springer. 1987. Leukocyte adhesion deficiency: an inherited defect in the Mac-1, LFA-1, and p150,95 glycoproteins. Annu. Rev. Med. 38:175-194.

27. Ameisen, J. C., and A. Capron. 1991. Cell dysfunction and depletion in AIDS: the programmed cell death hypothesis. Immunol. Today. 12:102-105.

28. Groux, H., G. Torpier, D. Monte, Y. Mouton, A. Carpon, and J. C. Ameisen. 1992. Activation-induced death by apoptosis in $\mathrm{CD}^{+} \mathrm{T}$ cells from human immunodeficiency virus-infected asymptomatic individuals. J. Exp. Med. 175:331-340.

29. Banda, N. K., J. Bernier, D. K. Kurahara, R. Kurrle, N. Haigwood, R. P. Sekaly, and T. H. Finkel. 1992. Crosslinking CD4 by human immunodeficiency 
virus gp120 primes $\mathrm{T}$ cells for activation-induced apoptosis. J. Exp. Med. 176:1099-1106

30. Oyaizu, N., T. W. McCloskey, M. Coronesi, N. Chirmule, V. S. Kalyanaraman, and S. Pahwa. 1993. Accelerated apoptosis in peripheral blood mononuclear cells (PBMCs) from human immunodeficiency virus type-1 infected patients and in CD4 cross-linked PBMCs from normal individuals. Blood. 82:3392-3400.

31. Mastino, A., S. Grelli, M. Piacentini, S. Oliverio, C. Favalli, C. F. Perno, and E. Garaci. 1993. Correlation between induction of lymphocyte apoptosis and prostaglandin E2 production by macrophages infected with HIV. Cell. Immunol. 152:120-130.

32. Koopman, G., and S. T. Pals. 1992. Cellular interactions in the germinal center: role of adhesion receptors and significance for the pathogenesis of AIDS and malignant lymphoma. Immunol. Rev. 126:21-45.

33. Savill, J., V. Fadok, P. Henson, and C. Haslett. 1993. Phagocyte recognition of cells undergoing apoptosis. Immunol. Today. 14:131-136.

34. Meagher, L. C., J. S. Savill, A. Baker, R. W. Fuller, and C. Haslett. 1992. Phagocytosis of apoptotic neutrophils does not induce macrophage release of thromboxane $\mathrm{B}_{2}$. J. Leukocyte Biol. 52:269-273.

35. Tabibzadeh, S. S., Q. F. Kong, and S. Kapur. 1994. Passive acquisition of leukocyte proteins is associated with changes in phosphorylation of cellular proteins and cell-cell adhesion properties. Am. J. Pathol. 145:930-940.

36. Daniel, V., C. Susal, R. Weimer, R. Zimmerman, A. Huth-Kuhne, and G. Opelz. 1993. Association of $T$ cell and macrophage dysfunction with surface gp120-immunoglobulin-complement complexes in HIV-infected patients. Clin. Exp. Immunol. 152-156.

37. Kobayashi, K., A. Takeda, S. Green, C. U. Tuazon, and F. A. Ennis. 1993. Direct detection of infectious human immunodeficiency virus type 1 (HIV-1) immune complexes in the sera of HIV-1 infected persons. J. Infect. Dis. 168:729732 .

38. Oh, S. K., W. W. Cruikshank, J. Raina, G. C. Blanchard, W. H. Adler, J. Walker, and H. Kornfeld. 1992. Identification of HIV-1 envelope glycoprotein in the serum of AIDS and ARC patients. J. Acquired Immune Defic. Syndr. 5:251256.

39. Krapf, F. E., M. Herrman, W. Leitmann, B. Schwartlander, and J. R. Kalden. 1990. Circulating immune complexes in HIV-infected persons. Klin. Wochenschr. 68:299-305.

40. Hymes, K., M. Nardi, A. Leaf, and S. Karpatkin. 1993. Role of leuCAM integrins and complement in platelet-monocyte rosette formation induced by immune complexes of human immunodeficiency virus-type 1-immune thrombocytopenic purpura patients. Blood. 81:2375-2380.

41. Liegler, T. J., and D. P. Stites. 1994. HIV-1 gp120 and anti-gp120 induce reversible unresponsiveness in peripheral blood CD4 T lymphocytes. J. Acquired Immune Defic. Syndr. 7:340-348.

42. Gherardi, R. K., C. Mhiri, M. Baudrimont, E. Roullet, J. P. Berry, and
J. Poirier. 1992. IgA nephritis in HIV-positive patients: a new HIV-associated nephropathy? Clin. Nephrol. 38:61-68.

43. McKeating, J. A., P. D. Griffiths, and R. A. Weiss. 1990. HIV susceptibility conferred to human fibroblasts by cytomegalovirus-induced Fc receptor. Nature (Lond.). 343:659-661.

44. Takeda, A., C. U. Tuazon, and F. A. Ennis. 1988. Antibody-enhanced infection by HIV-1 via Fc receptor-mediated entry. Science (Wash. DC). 242:580.

45. Matsuda, S., M. Gidlund, F. Chiodi, A. Cafaro, A. Nygren, B. Morein K. Nilsson, E. M. Fenyo, and H. Wigzell. 1989. Enhancement of human immunodeficiency virus (HIV) replication in human monocytes by low titres of anti-HIV antibodies in vitro. Scand. J. Immunol. 30:425-434.

46. Haubrich, R. H., A. Takeda, W. Koff, G. Smith, and F. A. Ennis. 1992. Studies of antibody-dependent enhancement of human immunodeficiency virus (HIV) type 1 infection mediated by Fc receptors using sera from recipients of recombinant gp160 experimental HIV-1 vaccine. J. Infect. Dis. 165:545-548.

47. Zeira, M., R. A. Byrn, and J. E. Groopman. 1990. Inhibition of serumenhanced HIV-1 infection of U937 monocytoid cells by recombinant soluble CD4 and anti-CD4 monoclonal antibody. Aids Res. Hum. Retroviruses. 6:629-639.

48. Connor, R. I., N. B. Dinces, A. L. Howell, L. J. L. Romet, J. L. Pasquali, and M. W. Fanger. 1991. Fc receptors for IgG (Fc gamma Rs) on human monocytes and macrophages are not infectivity receptors for human immunodeficiency virus type 1 (HIV-1): studies using bispecific antibodies to target HIV-1 to various myeloid cell surface molecules, including the Fc gamma R. Proc. Natl. Acad. Sci. USA. 88:9593-9597.

49. Murphy, P. M., H. C. Lane, A. S. Fauci, and J. I. Gallin. 1988. Impairment of neutrophil bactericidal capacity in patients with AIDS. J. Infect. Dis. 158:627630

50. Capsoni, F., F. Minonzio, A. M. Ongari, G. P. Rizzardi, A. Lazzarin, and C. Zanussi. 1992. Monocyte-derived macrophage function in HIV-infected subjects: in vitro modulation by rIFN-gamma and rGM-CSF. Clin. Immunol. Immunopathol. 62:176-182.

51. Wright, S. D., L. S. Craigmyle, and S. C. Silverstein. 1983. Fibronectin and serum amyloid $\mathrm{P}$ component stimulate $\mathrm{C} 3 \mathrm{~b}$ - and $\mathrm{C} 3 \mathrm{bi}$-mediated phagocytosis in cultured human monocytes. J. Exp. Med. 158:1338-1343.

52. Pommier, C. G., S. Inada, L. F. Fries, T. Takahashi, M. M. Frank, and E. J. Brown. 1983. Plasma fibronectin enhances phagocytosis of opsonized particles by human peripheral blood monocytes. J. Exp. Med. 157:1844-1854.

53. Haas, J. G., G. Riethmuller, and H. W. Ziegler-Heitbrock. 1987. Monocyte phenotype and function in patients with the acquired immunodeficiency syndrome (AIDS) and AIDS-related disorders. Scand. J. Immunol. 26:371-379.

54. Dransfield, I., D. Corcoran, L. J. Partridge, N. Hogg, and D. R. Burton. 1988. Comparison of human monocytes isolated by elutriation and adherence suggests that heterogeneity may reflect a continuum of maturation/activation states. Immunology. 63:491-498. 